\title{
Men's experience of erectile dysfunction after treatment for colorectal cancer: qualitative interview study
}

\author{
(@) (1) $\Theta$ OPEN ACCESS
}

\author{
George Dowswell research fellow ${ }^{1}$, Tariq Ismail consultant surgeon ${ }^{2}$, Sheila Greenfield senior \\ lecturer $^{1}$, Sue Clifford trial manager ${ }^{1}$, Beverley Hancock research fellow ${ }^{1}$, Sue Wilson professor of \\ clinical epidemiology ${ }^{1}$
}

${ }^{1}$ Cancer and Chronic Disease Team, Primary Care Clinical Sciences, University of Birmingham, Edgbaston, Birmingham B15 2TT, UK; ${ }^{2}$ University Hospitals Birmingham NHS Foundation Trust, Queen Elizabeth Hospital, Birmingham, UK

\begin{abstract}
Objectives To examine the experiences of men after treatment for colorectal cancer, identify barriers to accessing services, and suggest improvements to providing information in primary and secondary care.

Design Semistructured, qualitative interview study with purposive sampling and thematic analysis.

Participants 28 patients treated for colorectal cancer.

\section{Setting West Midlands.}

Results Most men treated for colorectal cancer experience erectile dysfunction as a consequence. Not all, however, want the same response from health professionals. Although, erectile dysfunction is profoundly stressful for most men, affecting self image, behaviour, and relationships, some do not regard it as a health priority. Many of the men were uninformed about erectile dysfunction and were unprepared for it, and the majority neither helped themselves nor asked for help. Almost none were receiving adequate, effective, and affordable care. Evidence of ageism was strong.
\end{abstract}

Conclusions Unlike patients with prostate cancer, men with colorectal cancer are not routinely offered information and treatment for erectile dysfunction. Greater coordination of care and consistent strategies are needed to tackle the unmet needs of this widely diverse patient group. Currently, clinicians are inadvertently neglecting, misleading, and offending such patients; better training could improve this situation, as might the reorganisation of services. Further research is needed to determine whether trained clinical nurse specialists in colorectal cancer units could coordinate ongoing care.

\section{Introduction}

Colorectal cancer is common, affecting over 38000 people each year in the United Kingdom, ${ }^{1}$ with about $50 \%$ of patients surviving for more than five years after treatment. ${ }^{2}$ With improvements in treatments and an ageing population the number of people surviving cancer will continue to increase. Men are more likely than women to develop colorectal cancer. ${ }^{3}$ A recent, large UK survey found that $75 \%$ of men had erectile dysfunction after treatment for colorectal cancer. ${ }^{4}$ Although sexual functioning declines with age, sexuality remains important to many men into old age. ${ }^{5}$ A growing body of literature is accumulating on survivorship after cancer and sexual function, ${ }^{6-8}$ but published studies describing the erectile dysfunction experience of patients with colorectal cancer to underpin service development are insufficient.

Studies on patients after surgery for prostate cancer provide some potentially useful insights and have shown that erectile dysfunction has an important detrimental impact on quality of life for men and their partners. Over $60 \%$ of men have been found to be distressed by erectile dysfunction after radical prostatectomy. ${ }^{9}{ }^{10}$ Although men have reported having no diminished interest in sex after surgery, they felt less masculine and described much lower sexual activity, capability, and enjoyment. ${ }^{5}$ Men described reductions in the quality of sexual intimacy, sexual fantasy, perceptions of masculinity, and general social interactions with women, along with physical discomfort during sex. The greatest distress was reported by men with the lowest sexual functioning and highest sexual desire. ${ }^{11}$ Patients with prostate cancer who felt inadequately informed and uninvolved in decisions about treatment were more likely to regret having treatment. ${ }^{5}{ }^{12}$ This finding may be particularly pertinent for patients with colorectal cancer, many of whom are unaware of links between the surgery and erectile dysfunction.

Most of the evidence on treatment for erectile dysfunction and the impact of treatment on men's experience has also emerged from studies focusing on prostate cancer. Phosphodiesterase 
type 5 inhibitors such as sildenafil (Viagra) are widely and successfully used for post-surgical erectile dysfunction in patients with prostate cancer, ${ }^{13}{ }^{14}$ although it is known that unsuccessful treatment with phosphodiesterase type 5 inhibitors may reduce quality of life still further. ${ }^{15}$ However, the physical and psychological causes of erectile dysfunction in men with colorectal cancer and prostate cancer may not be the same. ${ }^{16}$ Evidence on the use and effects of phosphodiesterase type 5 inhibitors after pelvic surgery for colorectal cancer is limited ${ }^{17}$ and it has not become part of routine planning after surgical treatment.

The way that men experience erectile dysfunction may be mitigated by the timeliness and quality of information available to them. Finding appropriate information and treatment on erectile dysfunction may be difficult for patients ${ }^{18}$ and the important role of the multidisciplinary team in providing information before and after surgery has been highlighted. ${ }^{19}$ There have been calls for healthcare professionals to give more assistance to survivors of cancer to help them adjust to treatment related erectile dysfunction, changed sexual function, and impaired sense of masculinity. ${ }^{5}$ Most clinicians, however, avoid discussing sexual matters, ${ }^{20}$ and patients often fail to raise social and emotional issues. ${ }^{21}$ Unvoiced patient agendas often lead to misunderstandings, dissatisfaction, and poor outcomes. ${ }^{22}$

Findings from studies focusing on prostate cancer, particularly those relating to the impact of treatment on men's experiences of erectile dysfunction may be only partly applicable to men with colorectal cancer. To date there has been little published research describing the experiences of erectile dysfunction in men with colorectal cancer, ${ }^{8}$ or their views and preferences about information, services, and treatment. We carried out a qualitative study to describe the experiences of men with erectile dysfunction after surgery for colorectal cancer and to ascertain whether or not the provision of information could be improved so that it is "flexible, responsive to individual's coping strategies and information choices." 23

\section{Methods}

We carried out a prevalence study of erectile dysfunction among 378 paticipants who had a diagnosis of colorectal cancer between January 1998 and December 2008 and were treated in the same hospital trust in the West Midlands. These participants were invited to take part in a qualitative study. From the 167 men who agreed to be interviewed we selected those from a variety of backgrounds and with differing treatment histories to ensure a broad range of views and experiences of erectile dysfunction and to include minority views. ${ }^{24} \mathrm{We}$ used purposive sampling to select 28 men who had received treatment for colorectal cancer. The participants encompassed a diverse range of characteristics, including age, socioeconomic group, ethnicity, type of relationship, range of international index of erectile function scores ${ }^{25}$ adjuvant therapy, and presence of a stoma.

To elicit the men's beliefs and experiences on this sensitive topic we used semistructured face to face interviews. ${ }^{26-28}$ The interviews focused on beliefs about erectile dysfunction, impact on self perception and relationships, satisfaction with information, and experience of treatment (box 1). Analysis occurred concurrently with data collection so that emerging topics could be explored in later interviews. We gave the participants a choice of venue (own home or healthcare location) and sex of interviewer. Interviews were recorded and transcribed in full. Three of the researchers (GD, BH, and SG)

independently analysed the data using framework analysis. ${ }^{29}$

NVivo8 software was used to code and review themes (www. qsrinternational.com/). Frequent discussions within the team ensured thorough and consistent coding and led to the development of an extensive thematic framework, including both manifest (explicit) and latent themes. To aid understanding of the location and meaning of different themes and the relation between them we have reported data in tables, with supplementary explanations and examples. ${ }^{30}$ These tables were, however, derived from a purposive sample and should not be taken to represent the population; rather, we aimed to capture the range and diversity of experience, beliefs, and opinions instead of providing a quantitative summary of findings. ${ }^{31}$

\section{Results}

Twenty eight men with colorectal cancer (nine of whom had rectal cancer) were interviewed between March and June 2009. All the men chose a female interviewer, therefore BH carried out the interviews, which lasted between 10 and 126 minutes (mean 40 minutes). Most of the participants were married, white, and heterosexual; they varied considerably in age and International Index of Erectile Function score (table $1 \Downarrow$ ). Most had undergone colorectal cancer surgery $(n=24)$ and chemotherapy $(n=20)$, some had radiotherapy $(n=13)$, and some had a stoma $(\mathrm{n}=13)$. The cancer site was unknown in six, diffuse in one, above the rectosigmoid junction in 12, and below the rectosigmoid junction in nine. As four men did not have erectile dysfunction, the results concentrate on the experience of the other 24 who did.

\section{Characteristics of men in sample}

The thematic framework developed into a descriptive model that included important contextual factors (related to patients, partners, and health professionals) and reflected the process of experiencing cancer, developing erectile dysfunction, seeking help (or not), receiving treatment (or not), and positive or negative outcomes (figure $\downarrow$ ) The participants were heterogeneous in a general sense (social circumstances, occupational group, self image, life history, views of health services) and specifically (previous erectile dysfunction, continuing importance of sex, presence of a partner, relationship with partner and with general practitioner). All had received treatment for colorectal cancer.

\section{Causal beliefs and experience of erectile dysfunction}

A range of beliefs were expressed about the causes of erectile dysfunction (table $2 \Downarrow$ and box 2 ). Some men gave several explanations. For three, erectile dysfunction had predated colorectal cancer (owing to prostate or long term health problems). The rest of the men had become aware of erectile dysfunction at some point after surgery or adjuvant therapy although pinpointing the precise times of onset was difficult. Initial unawareness of erectile dysfunction stemmed from morbidity, the side effects of treatment (severe in some cases), and the shock from or preoccupation with having cancer. Some may also have associated erectile dysfunction with other treatment (blood pressure tablets, for example). After treatment, and following a period of recovery, most of the sample $(n=19)$ attributed the onset of erectile dysfunction to the effects of treatments for colorectal cancer. Around half the men, however, believed that continuing erectile dysfunction was related to a range of psychological factors. Only a quarter attributed erectile dysfunction to age or poor general health. 


\section{Box 1: Semistructured interview questions and topic guide}

- Brief review of history of diagnosis and treatment for colorectal cancer (to validate information on background characteristics and to establish rapport)

- Refer to responses to the questionnaire and ask about: the nature of the interviewee's erectile dysfunction

when problems started (to check whether erectile dysfunction started before post-surgical treatment or before either surgery or diagnosis)

- What information about erectile function was provided (if any) before or after surgery and by whom Satisfaction/dissatisfaction with information provision

- Explore the interviewee's experience of erectile dysfunction: how he feels about his problems

the effect it has on him: relationships, self esteem, wellbeing

- Has the interviewee sought any help, advice, or treatment? if so, what, where from, has it helped?

if not, what are the reasons

- How should potential problems of erectile dysfunction be broached with patients? what information should be provided?

by whom?

at what stage: after diagnosis, before or after surgery, at follow-up?

what options for help or treatment would the interviewee like to see made available?

- Closing topic

Key messages for healthcare professionals about informing patients about potential problems and management of erectile dysfunction

\section{Box 2: Causal beliefs about erectile dysfunction (also see table 2)}

\section{Treatment related}

As soon as I had the [colorectal cancer] operation, as soon as I was sort of well enough, I found out nothing was sort of happening kind of thing (patient 118)

After I came off chemo ... I thought to myself, I said, "I can't get a hard on" (312)

It's either the radio or the chemo. I can't define which one it is. I think it was the radiotherapy, and I think they've done some damage there (404)

Psychological

And I think the thing was that the harder I tried the worse it got, you know. So I just . . . (374)

Yeah you get very depressed [Question: does that contribute to erectile dysfunction?] . . . probably psychologically because I mean a lot of it's in your mind isn't it, I think (319)

as a man you do feel a failure, I guess, and not a man, or unmanly, or, you know. Your sort of kind of macho or masculinity is sort of undermined, I guess. I know initially, it was very physical and ... then it becomes a more of a psychological thing ... it becomes a vicious circle (105)

I suppose all those factors do come into it especially the situation that I'm in now, I'm on my last lap, so you start to think about what's going to happen, what's going to happen to your wife, your kids, you know you've got the mortgage to take care of, I don't know what's going to happen to the house, who's going to be looking after them, you know who's going to be paying for the mortgage and all those monetary things do come in (79)

Physical condition

Well I would have taken it to be old age to be quite honest, at 71 you can't expect to lead the full drama (125)

I think my health, obviously, had a big aspect in that. And probably, what do you call it. And because you are ill you lose the desire to have sex, if you like, it's as simple as that. I think because you're feeling so bad (347)

\section{Experience of erectile dysfunction}

Before and during treatment all participants agreed that tackling the cancer was their main objective. When treatment stopped, however, the men described a diverse range of effects of erectile dysfunction on themselves and on their partners. Profound and stressful consequences were reported as erectile dysfunction challenged the men's identity, affected mental and physical health, and undermined relationships (box 3). At one extreme suicide was contemplated; a minority of the men accepted these changes philosophically and with a degree of stoicism.

\section{Help seeking (or not)}

Thirteen men never sought help for erectile dysfunction, whereas nine others sought no further help after unsuccessful treatment (figure, table 3 , $\Downarrow$ and box 4 ).

Men usually gave more than one reason for their help seeking behaviour. Notably, men who had received treatment appeared less reticent but otherwise shared most of the views of the men who had never asked for help.

Reticence was the most common explanation for not seeking help. This encompassed simple embarrassment (four men), a lack of confidence, a general fear of looking stupid, and waiting to be asked rather than raising the subject themselves. Some men had not even discussed erectile dysfunction with their partners. Four men expressed low expectations of clinicians (based on poor care experiences) and believed that responses would be offensive. Three men believed they had already had their "fair share" of care, and two stated that if they were "greedy" it meant that others would be deprived of care.

The category of risk encompassed perceptions that clinicians in primary and secondary care were too busy (in general) and not interested in erectile dysfunction (in particular). Six men perceived that erectile dysfunction was not on the clinical agenda and therefore did not want to risk raising it in case this was deemed inappropriate. Three thought it might give offence to 


\section{Box 3: The experience of erectile dysfunction}

I think. I'd like to sort of feel that I was a complete man really and you don't feel like you're a complete man really and it's not a very nice feeling. It's like, I don't know, you can imagine how these women feel who have a breast op, they don't feel they're a complete woman I would imagine. It's like a piece of you is not there, you're not quite a full person are you? (90)

It only hits you then. I'm going, I'm useless. It's only for peeing now, if you know what I mean (312)

Because I mean in darkest moments you do think well I wonder if it was worth having to be like existing like this, it's not really living (319)

it's very difficult to describe all the emotions and everything else that you go through and the pain that you suffer and the anguish and the frustration and everything else, all rolled into one. It's a very ... it's a very straining time, both on relationships and on your mental health (347)

We enjoyed a good sexual relationship. the relationship isn't the same, it isn't the same. You can sense it isn't the same and the frustration, you know, it creates frustration. So the relationship, it hasn't broke down yet but I suspect it will (264)

we've had a couple or three goes in the last 12 months, that's probably it. Instead of three a day, I'm, you know, I'm on three a year now. Which is quite a bit of difference (328)

because l'm not desperate for sex, l'm desperate to become well. My worry is to be a proper man that's it (429)

So I don't know in my heart of hearts what my wife's feeling about it is or was, but I know that she was probably keener than me (457)

\section{Box 4: Not seeking help}

Reticence

[Have you told your surgeon that the general practitioner refuses to prescribe phosphodiesterase type 5 inhibitors?]: No. Because he's never asked (312)

I don't know, probably embarrassment. And the other thing is probably in one sense probably the stock answer might be back "oh well, look at your age like," you know, type of thing and "you've just had this operation, what do you expect" type of thing. I have probably expected that in my mind's eye and think well okay it might be the norm, I don't know. If it is then you just live with it (347)

Risk

But I do feel that [consultant A] is so busy ... as [consultant B] pointed out when I said that I was going to see [consultant A], he's pointed out he's a very busy man. Now I don't want to ruffle anybody's feathers and I'm reluctant to phone secretaries or make myself a nuisance because I do feel that he's doing me a favour. He's doing me a favour insomuch as he's taking me back on again so I feel in that position $(264)$

Temporal

I link it all to all these things I'm taking and the operations and I'm just hoping that it'll go. Something ... it's a cycle and something will change again in me (374)

I will get around to it, I will get round to it, yeah (328)

\section{Relevance}

Maybe if none of this had happened and that had happened, I may have had more of a problem with it. But I'm more accepting because of what's ... what l've had done to me recently (412)

lgnorance

I've had [an appointment] for the stoma nurses but l've never considered them to be the ones to ask about this problem ... didn't realise that they were the people to approach (118)

the clinician and feared that being "pushy" would undermine future care. Under the temporal reasons, four men were optimistically waiting for erectile dysfunction to resolve naturally, two were procrastinating, and three explained that it had been relatively unimportant while undergoing active cancer treatment and so had only recently emerged as a problem. Relevance was questioned by five men who did not believe that erectile dysfunction was a great concern to them or thought that it was irremediable. Two men, in the category of ignorance, simply did not understand how to get help from the healthcare system.

Inactive help seekers could be subdivided into those who had ceased sexual activity (with or without partners), those who wanted help from their general practitioner (but could not ask), and those waiting for someone other than their general practitioner to offer help.

\section{Experience of treatment for erectile dysfunction}

Ten men had sought treatment for erectile dysfunction. Diverse experiences were reported in initiating help, the response of clinicians, and the outcome of treatment.

\section{Initiating help}

Four men took the initiative and directly approached their general practitioner for help, three were offered help by their general practitioner (one man's wife had asked the doctor to do so), one man and another man's wife had asked the consultant (both referred to general practitioner), and one man had asked the stoma nurse (referred to consultant and general practitioner):

once all my treatment had finished I talked it over with [consultant] at one of his clinics and he said to see my own general practitioner (319)

\section{Clinicians' responses and outcomes}

The men's experiences were diverse. One was told by his general practitioner that he was not eligible for phosphodiesterase type 5 inhibitors (no surgery) and gave up at this point. Another was referred by an andrologist to his general practitioner for a new drug, which the general practitioner refused to prescribe (lost paperwork, perceived lack of knowledge, and unacceptable cost to the National Health Service). Eight received phosphodiesterase type 5 inhibitors (only one reported obtaining a free prescription): one reported that it worked but resented that he couldn't afford it on prescription so bought it cheaper on the internet, one said it worked at first but not subsequently; four said it didn't work (one had tried four different types), one 
said that he disliked it (unspontaneous), and one had been too nervous to try it as a result of severe genital burns from radiotherapy. One had subsequently obtained the aphrodisiac horny goat weed from the internet (not efficacious). Two of those who experienced a lack of benefit also reported increased rejection by partner and subsequent dejection (echoing views of some who had not sought treatment). In addition, one man had also tried "sticks put down the penis" (unsuccessfully) and another was persevering with a pump device:

I have tried it [Viagra]. I got it off internet. The doctor won't give it so I've got to pay for everything. I'm not entitled to this, I'm not entitled to that. I said, I'd only just gone through chemo and all that, and I says, I can't get an erection unless I have the Viagra and I said, it's started destroying me, it's doing my head in (312)

Yeah, I didn't like it. I tried it about twice, I couldn't stand it [lack of spontaneity] (374)

I've looked on the internet, they said that horny goat weed and things like this might work ... it gives me headaches ... But my impression of that was again you got a reasonable amount of desire but you're not able to fulfil what your mind and your body's saying you want to fulfil (90)

\section{Inadequacies of patient care; information before, during, and after cancer treatment Preparation}

Only two people independently sought information on erectile dysfunction. Although most participants reported being given general information, more than half of the men who developed erectile dysfunction after treatment for colorectal cancer believed that they had not been warned specifically about erectile dysfunction:

\section{[erectile dysfunction] I presumed it to be an effect of chemotherapy which surprised me, I did some Googling and found that it was in fact most likely an effect from the surgery and to be honest I was annoyed that I didn't know about it (24)}

However, all pointed out that they would still have had the treatment even if more adequately informed. Ten men recalled receiving verbal information from a nurse or doctor on possible erectile dysfunction, some of which was unintentionally offensive. Eight of those men recalled receiving written information. There seemed to be a strong trend for clinicians to offer the most information and help to younger men and for the greatest offence to be given to patients perceived to be "too old" (many of whom perceived themselves as quite young, both physically and sexually):

Yes, my stoma nurse, in the beginning when they first found out it was cancer, said because of the surgery things can happen, she said, but Viagra will sort it out (321)

But he said "at your age I don't think it will matter" and he was nearly as old himself (Laughs) I thought "that's a bloody cheek." You know, I said to myself "well he's nearly as old as me" (78, aged 72)

She advised me I shouldn't consider having children while under chemotherapy ... she said "I don't suppose this is a great concern to you at your age" (24, aged 61)
These men acknowledged the difficulty of taking in information, either because it was unimaginable or because they were still coming to terms with their cancer diagnosis:

If they said, you won't talk again, it doesn't matter. If they say you'll never be able to make love again, it doesn't matter. Right ho, I'm going to make love for the next six months and then I'm dead. It doesn't matter. Everything will go immediately once you're told "cancer" (321)

\section{Treatment}

If patients asked about possible erectile dysfunction, positive (but inadvertently misleading) information was given:

[the] nurse gave me the injection, I did ask the nurse will this interfere with any sexual activity and her reply to that was "oh you'll be perfectly okay, we have tablets for that" (264)

\section{Aftercare}

When the men began to recover from the effects of cancer and its treatment, many began to take an interest in erectile dysfunction:
Well at the time, that was pretty much in the back of my mind. I was more concerned about my bowel cancer and getting myself sorted out with that but you know, you sort of take it step by step and at the moment, this (erectile dysfunction) is the thing I'm trying to sort out (118)

Some had reached a point in their recovery where they felt swindled:

And that is part of the package which they really don't tell you about. It's like saying "well you're going on the package holiday, there's the hotel," but they don't tell you it's half built at the back do they? And there's no running water or whatever (347)

Although many men wanted reassurance, there was no universal form this could take:

When I did ask a question [of consultant], it was sort of a, you know, "yeah," "no," "possibly." And that was it (404)

Not all knew where to seek help for erectile dysfunction. Some men took part in our study specifically to ask for help and to get a sense of what the norms might be. No coordinated system of care for erectile dysfunction was apparent from accounts:

Well, this is why I've been in two minds about it because-who is best to consult? (347)

\section{Discussion}

Most men treated for colorectal cancer experience erectile dysfunction as a consequence. Not all of them, however, want the same response from health professionals. Although for most men erectile dysfunction is profoundly stressful, affecting self image, behaviour, and relationships, some do not see it as a health priority. Many of the men in our sample were uninformed about erectile dysfunction and were unprepared for it, and the majority neither helped themselves nor asked for help. Almost none were receiving adequate, effective, and affordable care. Evidence of ageism was strong. 


\section{Results in context}

Care pathways for patients with prostate cancer are designed to ensure that information about erectile dysfunction is incorporated into routine care and that treatment is offered. Neither information on nor treatment for erectile dysfunction is routinely offered to men with colorectal cancer; ${ }^{8}$ this may result from a lack of evidence on the effects of treatment or a lack of awareness among clinicians of the patient's need for treatment. Although men may not remain sexually active throughout their life course, it is reasonable to question whether patients with colorectal cancer have the same right to information and treatment for erectile dysfunction as those with prostate cancer.

Widespread evidence shows that men access health services less often than women..$^{32}$ Men tend to seek help only when it has been sanctioned by family or friends or when symptoms interfere with employment. ${ }^{33}$ As erectile dysfunction tends not to be discussed or to affect employment, this may explain why the majority of the men in our study did not access services. The sociological literature suggests that cultural norms- - "hegemonic masculinity"-prevent men from admitting weakness or vulnerability, promote emotional and physical control, and oblige them to uphold the appearance of strength. ${ }^{34-36}$ As most men are unwilling to disclose weakness ${ }^{35}$ this may mean that their needs are invisible. ${ }^{36}$ In more nuanced analyses, the dynamic and contextual nature of masculinity has been highlighted, although this also affirms that silence is usually the dominant and safest approach for men adjusting to erectile dysfunction. ${ }^{37}{ }^{38}$ One review article suggests that men's reluctance to voice their concerns may be exacerbated when they see male physicians. ${ }^{39}$

The majority of patients with cancer want to be informed about their illness. ${ }^{40}$ However, this differs in extent and changes during their illness. ${ }^{23}$ During treatment patients generally focus on tackling cancer and only consider the side effects of treatment at a later stage. ${ }^{5}$ Many patients make little effort to find information themselves, and although they prefer to be given information by doctors, they may resist information that is offered to them. ${ }^{41}{ }^{42}$ Men, older people, and poorer people seek less information about cancer. ${ }^{43}$ Patients have been dichotomised into those that want and actively seek information and those that do not. ${ }^{44}$ Many of our participants did want information but did not successfully seek it, suggesting that this binary classification is far too simple.

\section{Limitations of the study}

Erectile dysfunction and sex are sensitive topics and are not generally discussed. Unfamiliarity or discomfort may have resulted in men failing to be coherent or explicit when discussing their experiences or preferences. We suspect that men's information needs change over time, but a longitudinal study would be needed to show this. In common with other qualitative studies we cannot assume that our sample is representative; rather we set out to describe a range of views and experiences. However, comparison with the prevalence study population (table 1) shows that the participants who were interviewed were similar to the questionnaire respondents except that, because of the purposive sampling, they were slightly younger and less likely to be of white ethnicity.

\section{Implications for clinical practice}

In England inequalities in access to erectile dysfunction treatment currently exist. While clinical guidelines are inclusive ${ }^{45}$ health service guidelines seem to unfairly privilege patients with prostate cancer over those with colorectal cancer. ${ }^{46}$ They also exclude people who have not had surgery, ${ }^{47}$ although adjuvant therapies are known to cause erectile dysfunction. ${ }^{6}$

Participants' accounts suggested that care of patients after treatment for colorectal cancer is uncoordinated and reflect the popular beliefs (lay and clinician) that erectile dysfunction is easy to treat ${ }^{45}$ and that "Viagra works for everyone."

Phosphodiesterase type 5 inhibitors do not, however, work for large numbers of men ${ }^{48}$ and access to other treatments for these patients seems to be inadequate.

This study suggests three simple points for clinicians. Firstly, there is considerable potential for offending older men by making assumptions about their sexual behaviour or motivation. Older couples may not differ substantially from younger couples in sexual interest or activity. ${ }^{49}$ Secondly, phosphodiesterase type 5 inhibitors are not a panacea. Thirdly, the majority of men are not going to ask for help with erectile dysfunction and therefore it may be necessary for someone in the clinical team to explore this sensitively but routinely. Based on the evidence that erectile dysfunction is stressful and distressing, we suggest that the opportunity needs to be created for men to voice their concerns. We have not, however, established precisely how to get men to acknowledge that erectile dysfunction is important, common, a legitimate concern (whatever the patient's age or marital status), or acceptable as a topic of discussion with clinicians, and that addressing it is a reasonable component of healthcare for patients with colorectal cancer.

The wide diversity of this patient group (but a general lack of information, understanding, and limited help seeking) calls for a more proactive coordination of care and consistent strategies to address unmet needs. More work is needed to fully determine patients' and clinicians' views on the appropriate design and delivery of services. Previous work has shown that healthcare workers often avoid discussing erectile dysfunction because they have other priorities, may not recognise its importance to men's health related quality of life, and feel embarrassed themselves about discussing sexual matters. ${ }^{6}{ }^{20}$ Therefore we could speculate that responsibility needs to be explicitly given to a particular member of a team. Given appropriate training and support, colorectal clinical nurse specialists (a central part of most colorectal cancer care teams) could focus on the diverse needs of this variable population, incorporate the provision of information on erectile dysfunction into care before and after surgery, identify unmet needs, refer as necessary, monitor progress, and coordinate ongoing care. Oncology nurses in the United States and breast cancer nurses in the United Kingdom often have a similar role. ${ }^{6}$ A checklist (see web extra) is suggested by our descriptive framework (figure). Other practical solutions may also be possible.

\section{Future research}

Although we did not interview the spouses or partners of patients, their perspectives were strongly present in several accounts. If asked directly, they may have provided different and richer accounts. Further research is needed to tackle this gap. Purposive sampling enables the broad range of experience to emerge, but further work is needed to determine the true prevalence of the experiences and preferences uncovered here. A detailed assessment of the existing provision of information on erectile dysfunction is called for to determine what approaches are used in different centres and what impact these may have on men's understanding. Further research could also illuminate the clinicians' perspective on delivering tailored information to men with colorectal cancer and assess the impact 
of enhancing the coordinating role of colorectal clinical nurse specialists.

We thank Kesavapilla Subramonian (urologist), Annette Leyland (colorectal nurse specialist), Christine Gratus (lay member), and N Suggett (colorectal surgeon) who all contributed to steering group meetings and supported the study, and the men who participated in this study.

Contributors: TI had the idea for the study. TI, SW, and SG developed the study concept and design and obtained funding. All authors refined the study design through trial steering group meetings. TI provided clinical advice. SC and BH collected the data. SG, BH, and GD analysed the data. GD drafted the manuscript. All authors critically revised and approved the manuscript. SG is the guarantor.

Funding: This paper presents independent research commissioned by the National Institute for Health Research under the research for patient benefit programme (PB-PG-0407-13245). The views expressed in this publication are those of the authors and not necessarily those of the National Health Service, the National Institute for Health Research, or the Department of Health.

Competing interests: All authors have completed the ICMJE uniform disclosure form at www.icmje.org/coi_disclosure.pdf (available on request from the corresponding author) and declare: no support from any organisation for the submitted work; no financial relationships with any organisations that might have an interest in the submitted work in the previous three years; and no other relationships or activities that could appear to have influenced the submitted work.

Ethical approval: This study was approved by the Warwickshire Research Ethics Committee (08/H1211/122).

Data sharing: No additional data available.

1 Cancer Research UK. Bowel (colorectal) cancer-UK incidence statistics. 2010. http:// info.cancerresearchuk.org/cancerstats/types/bowel/incidence/.

2 Cancer Research UK. Bowel cancer statistics-key facts. 2010. http://info. cancerresearchuk.org/cancerstats/types/bowel/index.htm?script=true.

3 Payne S. Not an equal opportunity disease-a sex and gender-based review of colorectal cancer in men and women: part I. J Mens Health Gend 2007;4:131-9.

4 Ellis R, Smith A, Wilson S, Warmington S, Ismail T. The prevalence of erectile dysfunction in post-treatment colorectal cancer patients and their interests in seeking treatment: a cross-sectional survey in the West Midlands. J Sex Med 2010;7:1488-96.

5 Davison BJ, So Al, Goldenberg SL. Quality of life, sexual function and decisional regret at 1 year after surgical treatment for localized prostate cancer. BJU Int 2007;100:780-5.

6 Galbraith ME, Crighton F. Alterations of sexual function in men with cancer. Semin Oncol Nurs 2008;24:102-14.

7 Hordern A. Intimacy and sexuality after cancer: a critical review of the literature. Cancer Nurs 2008;31:E9-17.

8 Hendren SK, O'Connor BI, Liu M, Asano T, Cohen Z, Swallow CJ, et al. Prevalence of male and female sexual dysfunction is high following surgery for rectal cancer. Ann Surg 2005;242:212-23.

9 Schover LR, Fouladi RT, Warneke CL, Neese L, Klein EA, Zippe C, et al. Defining sexual outcomes after treatment for localized prostate carcinoma. Cancer 2002;95:1773-85.

10 Potosky AL, Davis WW, Hoffman RM, Stanford JL, Stephenson RA, Penson DF, et al. Five-year outcomes after prostatectomy or radiotherapy for prostate cancer: the prostate cancer outcomes study. J Natl Cancer Inst 2004;96:1358-67.

11 Dahn JR, Penedo FJ, Gonzalez JS, Esquiabro M, Antoni MH, Roos BA, et al. Sexual functioning and quality of life after prostate cancer treatment: considering sexual desire. Urology 2004;63:273-7.

12 Miles BJ, Giesler B, Kattan MW. Recall and attitudes in patients with prostate cancer. Urology 1999;53:169-74.

13 Incrocci L, Hop WC, Slob AK. Efficacy of sildenafil in an open-label study as a continuation of a double-blind study in the treatment of erectile dysfunction after radiotherapy for prostate cancer. Urology 2003;62:116-20.

14 Graham J, Baker M, Macbeth F, Titshall V. Diagnosis and treatment of prostate cancer: summary of NICE guidance. BMJ 2008;336:610-2.

15 Tomlinson J, Wright $D$. Impact of erectile dysfunction and its subsequent treatment with sildenafil: qualitative study. BMJ 2004;328:1037.

16 Sprangers MA, Taal BG, Aaronson NK, te Velde A. Quality of life in colorectal cancer. Stoma vs nonstoma patients. Dis Colon Rectum 1995;38:361-9.
17 Lindsey I, George B, Kettlewell M, Mortensen N. Randomized, double-blind, placebo-controlled trial of sildenafil (Viagra) for erectile dysfunction after rectal excision for cancer and inflammatory bowel disease. Dis Colon Rectum 2002;45:727-32.

18 Milne JL, Spiers JA, Moore KN. Men's experiences following laparoscopic radical prostatectomy: a qualitative descriptive study. Int J Nurs Stud 2008;45:765-74.

19 Phillips C, Gray RE, Fitch MI, Labrecque M, Fergus K, Klotz L. Early postsurgery experience of prostate cancer patients and spouses. Cancer Pract 2000;8:165-71.

20 Hordern AJ, Street AF. Constructions of sexuality and intimacy after cancer: patient and health professional perspectives. Soc Sci Med 2007;64:1704-18.

21 Campion PD, Butler NM, Cox AD. Principle agendas of doctors and patients in general practice consultations. Fam Pract 1992;9:181-90.

22 Barry CA, Bradley CP, Britten N, Stevenson FA, Barber N. Patients' unvoiced agendas in general practice consultations: qualitative study. BMJ 2000;320:1246-50.

23 Leydon GM, Boulton M, Moynihan C, Jones A, Mossman J, Boudioni M, et al. Cancer patients' information needs and information seeking behaviour: in depth interview study. BMJ 2000;320:909-13.

24 Patton MQ. Qualitative research and evaluation methods . 3rd ed. Sage, 2002

25 Rosen RC, Cappelleri JC, Smith MD, Lipsky J, Pena BM. Development and evaluation of an abridged, 5-item version of the International Index of Erectile Function (IIEF-5) as a diagnostic tool for erectile dysfunction. Int J Impot Res 1999;11:319-26.

26 Britten N. Qualitative interviews in medical research. BMJ 1995;311:251-3.

27 Denzin NK, Lincoln YS. Handbook of qualitative research . 2nd ed. Sage, 2000.

28 Lee RM. Doing research on sensitive topics. Sage, 1993.

29 Ritchie J, Lewis J. Qualitative research practice: a guide for social science students and researchers . Sage, 2003.

30 Seale C. The quality of qualitative research. Sage, 1999.

31 Selman L, Higginson IJ, Agupio G, Dinat N, Downing J, Gwyther L, et al. Meeting information needs of patients with incurable progressive disease and their families in South Africa and Uganda: multicentre qualitative study. BMJ 2009;338:b1326.

32 Galdas PM, Cheater F, Marshall P. Men and health help-seeking behaviour: literature review. J Adv Nurs 2005;49:616-23.

33 Smith LK, Pope C, Botha JL. Patients' help-seeking experiences and delay in cancer presentation: a qualitative synthesis. Lancet 2005;366:825-31.

34 Chapple A, Ziebland S, McPherson A. Qualitative study of men's perceptions of why treatment delays occur in the UK for those with testicular cancer. Br J Gen Pract 2004;54:25-32.

35 Charmaz K. Identity dilemmas of chronically ill men. In: Sabo D, Gordon D, eds. Men 's health and illness: gender, power and the body. Sage, 1995:266-91.

36 Courtenay WH. Constructions of masculinity and their influence on men's well-being: a theory of gender and health. Soc Sci Med 2000;50:1385-401.

37 Oliffe J. Health behaviors, prostate cancer, and masculinities: a life course perspective. Men and Masculinities 2009;11:346-66.

38 Wall D, Kristjanson L. Men, culture and hegemonic masculinity: understanding the experience of prostate cancer. Nurs Inq 2005;12:87-97.

39 Hall JA, Roter DL. Do patients talk differently to male and female physicians? A meta-analytic review. Patient Educ Couns 2002;48:217-24

40 Meredith C, Symonds P, Webster L, Lamont D, Pyper E, Gillis CR, et al. Information needs of cancer patients in west Scotland: cross sectional survey of patients' views. BMJ 1996;313:724-6.

41 Pinder R. The management of chronic illness: patient and doctor perspectives on Parkinson's disease. Macmillan, 1990.

42 Johnson JD. Cancer-related information seeking . Hampton Press, 1997.

43 Mayer DK, Terrin NC, Kreps GL, Menon U, McCance K, Parsons SK, et al. Cancer survivors' information seeking behaviors: a comparison of survivors who do and do not seek information about cancer. Patient Educ Couns 2007;65:342-50.

44 Ramanadhan S, Viswanath K. Health and the information nonseeker: a profile. Health Commun 2006:20:131-9.

45 Ralph D, McNicholas T. UK management guidelines for erectile dysfunction. BMJ 2000;321:499-503

46 National Institute for Health and Clinical Excellence. Prostate cancer: diagnosis and treatment. NICE clinical guideline 58. 2008. www.nice.org.uk/nicemedia/live/11924/39627/ 39627.doc.

47 National Health Service. NHS Choices website. 2010. www.nhs.uk/Conditions/Erectiledysfunction/Pages/Treatment.aspx.

48 Goldstein I, Lue TF, Padma-Nathan H, Rosen RC, Steers WD, Wicker PA. Oral sildenafil in the treatment of erectile dysfunction. Sildenafil Study Group. N Engl J Med 1998;338:1397-404

49 Lindau ST, Schumm LP, Laumann EO, Levinson W, O'Muircheartaigh CA, Waite LJ. A study of sexuality and health among older adults in the United States. N Engl J Med 2007;357:762-74.

\section{Accepted: 9 August 2011}

\section{Cite this as: BMJ 2011;343:d5824}

This is an open-access article distributed under the terms of the Creative Commons Attribution Non-commercial License, which permits use, distribution, and reproduction in any medium, provided the original work is properly cited, the use is non commercial and is otherwise in compliance with the license. See: http://creativecommons.org/licenses/by$\mathrm{nc} / 2.0 /$ and http://creativecommons.org/licenses/by-nc/2.0/legalcode. 


\section{What is already known on this topic}

Most men with colorectal cancer develop erectile dysfunction after treatment

Men tend to be reluctant to seek clinical help and are specifically reticent about sexual topics; clinicians are generally reluctant to initiate discussion about sexual function

Treatments for erectile dysfunction are not universally efficacious

\section{What this study adds}

Most men with colorectal cancer are not receiving adequate information, diagnosis, or treatment for erectile dysfunction after surgery

Clinicians are inadvertently neglecting, misleading, and offending patients with colorectal cancer; better training could improve this and reorganisation of services may help

Colorectal clinical nurse specialists are well placed to give information, coordinate treatment, and monitor progress

\section{Tables}

Table 1 | Characteristics of participants $(\mathbf{n}=\mathbf{2 8}$ ). Values are percentages (numerators/denominators) unless stated otherwise

\begin{tabular}{lccc} 
Characteristics & Interviews $(\mathbf{n}=\mathbf{2 8})$ & Prevalence survey $(\mathbf{n}=\mathbf{3 7 8})$ & Statistics \\
Mean (SD) age, (range) & $59.4(10),(34-80)$ & $65.9(9.8),(29-80)$ & $\mathrm{t}=3.38, \mathrm{df}=404, \mathrm{P}<0.001$ \\
\hline In sexual relationship & $61(17 / 28)$ & $55(192 / 346)$ & $\mathrm{X}^{2}=0.29, \mathrm{df}=1, \mathrm{P}=0.59$ \\
\hline Heterosexual & $96(26 / 27)$ & $97(341 / 351)$ & $\mathrm{X}^{2}=0.06, \mathrm{df}=1, \mathrm{P}=0.80$ \\
\hline Sex in past six months & $39(11 / 28)$ & $38(133 / 353)$ & $\mathrm{X}^{2}=0.03, \mathrm{df}=1, \mathrm{P}=0.87$ \\
\hline White ethnicity & $86(24 / 28)$ & $96(361 / 376)$ & $\mathrm{X}^{2}=6.16, \mathrm{df}=1, \mathrm{P}=0.01$ \\
\hline Surgery for colorectal cancer & $89(24 / 27)$ & $96(349 / 363)$ & $\mathrm{X}^{2}=3.17, \mathrm{df}=1, \mathrm{P}=0.07$ \\
\hline Mean (SD) years since admission (range) & $1.27,(1.9),(0-7)$ & $2.34,(2.6),(0-11)$ & $\mathrm{t}=1.89, \mathrm{df}=398, \mathrm{P}=0.06$ \\
\hline
\end{tabular}


Table 2| Causal beliefs about erectile dysfunction

Associated factors

No of men $(n=24)$

Treatment related $(n=19)$ :

\begin{tabular}{ll}
\hline Colorectal surgery & 9 \\
\hline Radiotherapy or chemotherapy & 8 \\
\hline Other treatment & 6 \\
\hline Psychological $(\mathrm{n}=12):$ & \\
\hline Tried and failed (fear and anxiety) & 4 \\
\hline Depressed & 3 \\
\hline Masculinity undermined & 2 \\
\hline Other & 6 \\
\hline Physical condition $(\mathrm{n}=6):$ & \\
\hline Age & 3 \\
\hline Health & 3 \\
\hline
\end{tabular}

Some men gave more than one reason. 
Table 3| Reasons for not seeking help for erectile dysfunction $(\mathbf{n = 2 2})$

Reasons Never asked $(n=13)$ Did not ask after treatment failure $(n=9)$ Total $(n=22)$

\begin{tabular}{llll}
\hline Reticence & 12 & 4 & 16 \\
\hline Risk & 5 & 4 & 9 \\
\hline Temporal & 6 & 3 & 9 \\
\hline Relevance & 3 & 2 & 5 \\
\hline Ignorance & 1 & 1 & 2
\end{tabular}




\section{Figure}

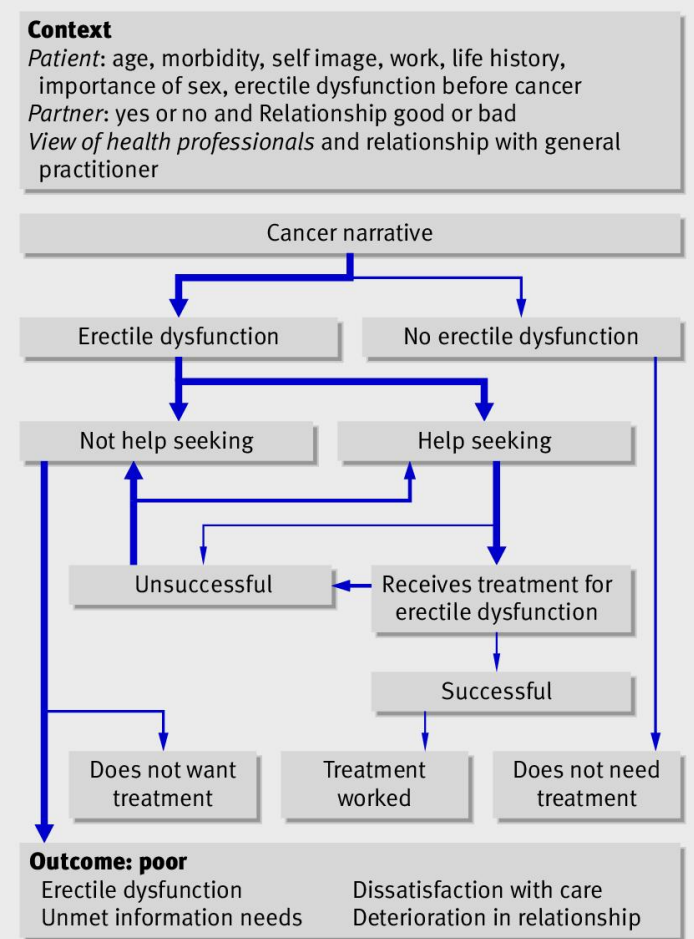

Patient pathways after colorectal cancer: width of lines gives some indication of numbers in each path

Fig 1 Thematic framework 